\title{
STUDYING TURBULENCE BY REMOTE SENSING SYSTEMS DURING SLOPE-2016 CAMPAIGN
}

\author{
Gregori de A. Moreira ${ }^{1,2,3, *}$, Juan L. Guerrero-Rascado ${ }^{2,3}$, Jose A. Benavent-Oltra ${ }^{2,3}$, Pablo \\ Ortiz-Amezcua $^{2,3}$, Roberto Róman ${ }^{2,3}$, Eduardo Landulfo ${ }^{1}$ and Lucas Alados-Arboledas ${ }^{2,3}$ \\ ${ }^{1}$ Institute of Energetic and Nuclear Research (IPEN), Brazil, * gregori.moreira @usp.br \\ ${ }^{2}$ Andalusian Institute for Earth System Research (IISTA-CEAMA), Spain \\ ${ }^{3}$ Dpt. Applied Physics, Faculty of Sciences, University of Granada, Spain
}

\begin{abstract}
The Planetary Boundary Layer (PBL) is the lowermost part of the troposphere. In this work, we analysed some high order moments and PBL height detected continuously by three remote sensing systems: an elastic lidar, a Doppler lidar and a passive Microwave Radiometer, during the SLOPE-2016 campaign, which was held in Granada from May to August 2016. This study confirms the feasibility of these systems for the characterization of the PBL, helping us to justify and understand its behaviour along the day.
\end{abstract}

\section{INTRODUCTION}

The planetary boundary layer (PBL) is defined as that "part of the troposphere that is directly or indirectly influenced by the presence of the Earth's surface (ground or sea), and responds to surface forcings with a time scale of a few hours or less." [1]. It is characterized by large variability in its statical stability and turbulence along the day. This behavior makes the detection of its height (PBLH) and the understanding of its turbulent characteristics very important for a wide set of studies, including pollutant dispersion and weather forecasting. However, this kind of study requires devices with high spatial and temporal resolution like as remote sensing systems (RSS) [2].

In this study, we use data from three RSS (Elastic Lidar $[E L]$, Doppler Lidar $[D L]$ and Microwave Radiometer $[M W R]$ ) acquired during SLOPE campaign, which was held in CEAMA (Andalusian Institute for Earth System Re- search - Granada [37.16 $\mathrm{N}, 3.61^{\circ} \mathrm{W}, 680 \mathrm{~m}$ asl $]$ - Spain) from May to August/2016, in order to analyze the height and turbulence in the PBL.

\section{METHODOLOGY}

Below it is described the methodology applied for the three RSS used in this paper.

\subsection{Microwave Radiometer (MWR)}

The RPG-HATPRO Radiometer Physics GmbH is a passive microwave radiometer, which performs measurements of the sky brightness temperature with a resolution between 0.3 and 0.4 $\mathrm{K}$ root mean square error at $1 \mathrm{~s}$ integration time. Beyond to providing temperature information at various heights, the MWR data were also used to identify the PBLH.

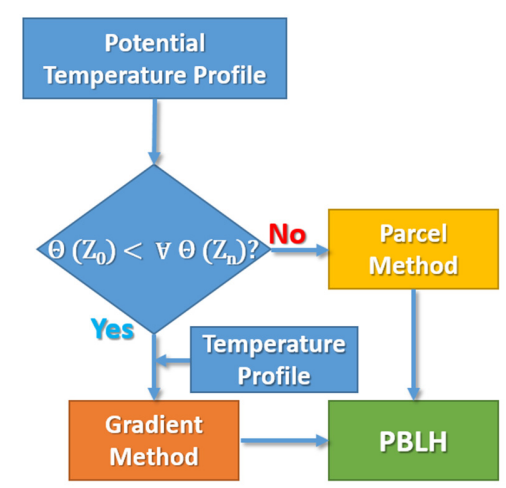

Figure 1: MWR Methodology

Figure 1 summarizes the methodology applied. It is made a comparison among surface temperature and the potential temperature profile $(\theta(Z))$ at within the firsts meters above the ground in order to identify if it has convective 
or stable characteristics. If it is detected as stable conditions $\left(\theta\left(Z_{0}\right)<\forall \theta\left(Z_{n}\right)\right)$ the gradient method [3] is applied on temperature profile, otherwise the Parcel Method [3] is selected.

\subsection{Elastic Lidar Mulhacén (EL)}

Mulhacén is an elastic-Raman lidar (Raymetrics Inc) operating at 355, 387, 408, 532 (paralell and perpendicular), 607 and $1064 \mathrm{~nm}$ with a temporal and spatial resolution of $2 \mathrm{~s}$ and 7.5 $\mathrm{m}$, respectively. This system is part of EARLINET (European Aerosol Research Lidar Network) since 2005 .

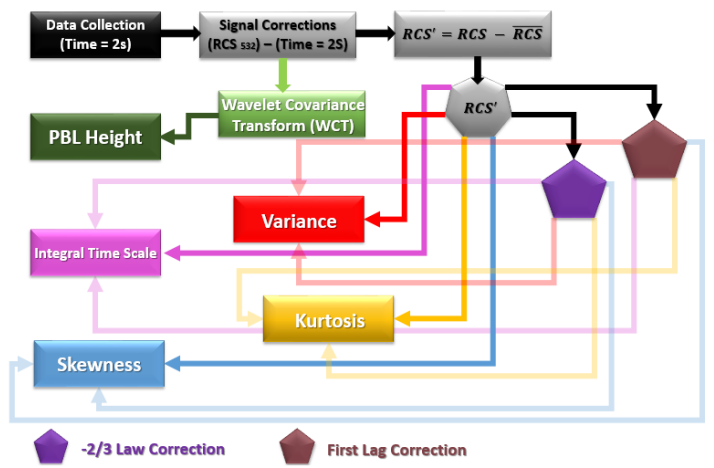

Figure 2: EL Methodology

In the Figure 2 there is a schematization of methodologies applied to study the PBL from EL data. The raw data collected are corrected for dark current, background radiation and square distance becoming the RCS (Range Corrected Signal). These data are used to identify:

- the PBLH by Wavelet Covariance Transform (WCT) Method [4];

- Integral Time Scale, which is the measure of the average size (in time) of the vortices involved in the PBL mixing processes:

$$
\tau=\int_{0}^{\infty} M(t) d t
$$

where $M(t)$ is the auto-covariance function of $R C S^{\prime}$

- Variance:

$$
\sigma^{2}=\frac{\sum_{i=1}^{N}\left(R C S_{i}^{\prime}-\overline{R C S^{\prime}}\right)^{2}}{N}
$$

where $N$ is the number of profiles.

- Skewness:

$$
S=\frac{\overline{R C S^{\prime 3}}}{R C S^{2^{2}}}
$$

- Kurtosis:

$$
K=\frac{\overline{R C S^{\prime 4}}}{{\overline{R C S^{\prime 2}}}^{2}}
$$

with its respective corrections: First Lag and $-2 / 3$ Law, which are direved from $M(t)$ [5].

\subsection{Doppler Lidar (DL)}

It is a Halo Photonics model Stream Line operating at $1.5 \mu \mathrm{m}$ with a temporal and spatial resolution of $2 \mathrm{~s}$ and $30 \mathrm{~m}$, respectively.

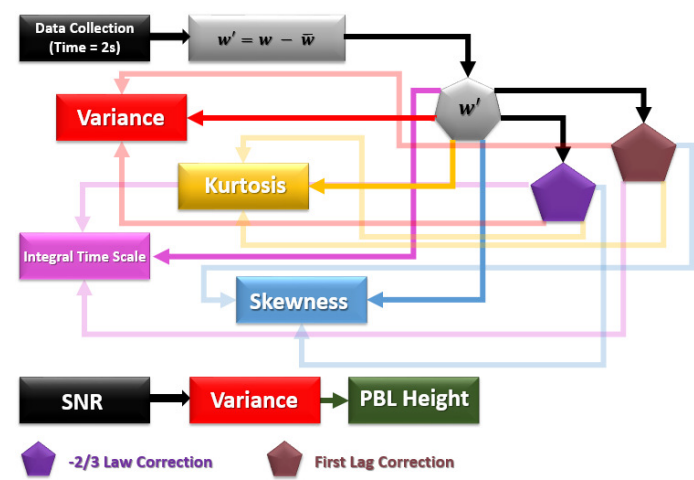

Figure 3: DL Methodology

Figure 3 shows the methodology applied to DL data, which is very similar to that presented previously for EL. The main difference is the variable used to study the high order moments, vertical wind speed $(w)$, and the use of Signal Noise Ratio (SNR) to identify the PBLH by variance method [6], instead of using RCS in both situations. 


\section{RESULTS AND DISCUSSION}

Figure 4 represents the integral time scale. The gray areas in the picture indicate heights where the integral time scale is lower than $2 \mathrm{~s}$ (DL time acquisition), therefore meaning that it is impossible to extract any information on the turbulence structures at these heights using DL. Thus, DL data provide information about turbulence throughout almost the whole PBL.

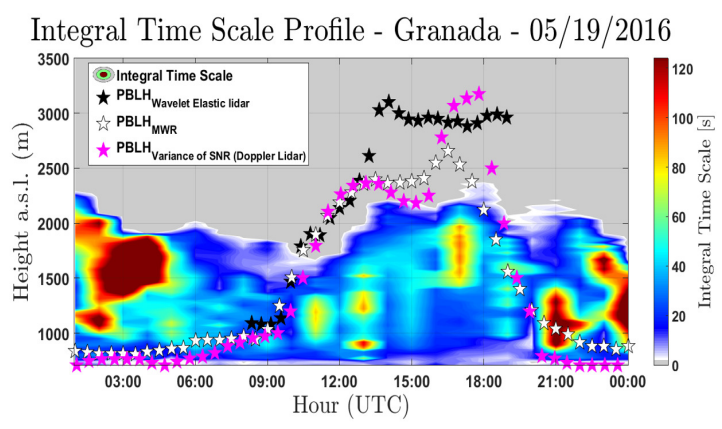

Figure 4: Integral Time Scale - DL

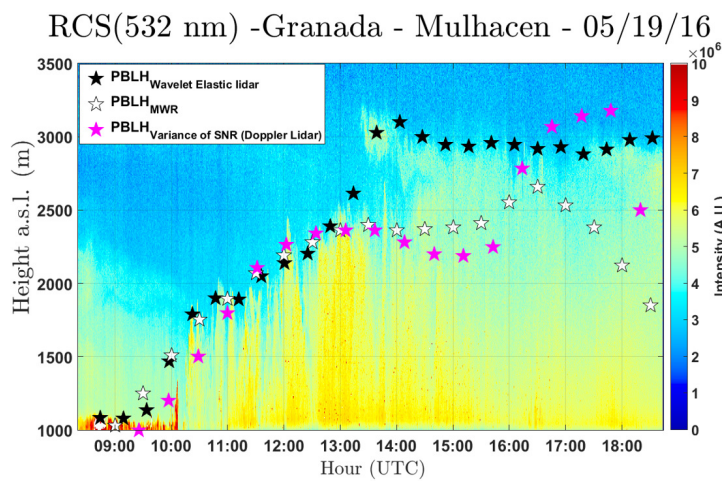

Figure 5: RCS profile - EL

In the same picture it is also possible to observe the PBLH detected by MWR, EL and DL, and we can notice that they are very similar, mainly during the PBL growing phase $(09-13 \mathrm{~h})$. In the middle of afternoon there is an ascension of an aerosol layer (Figure 5), and it causes some differences among the methods, but after some hours the PBLH obtained from EL and DL data return to coincide. During nocturnal phase PBLH from MWR and DL have a good agreement.

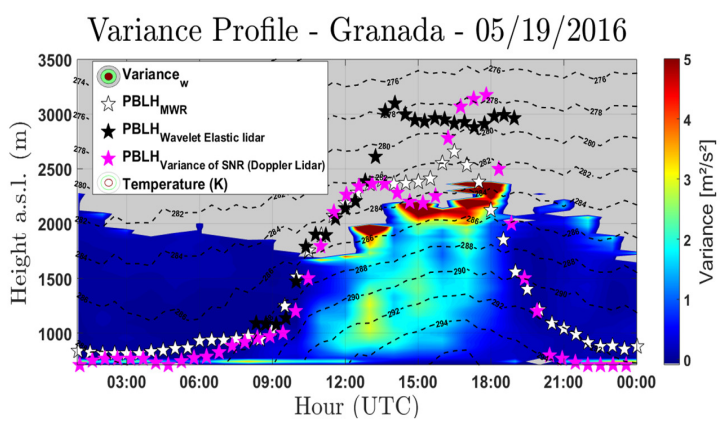

Figure 6: Variance - DL

The elevation and reduction of surface temperature directly affect the increase and decrease of the variance of $w$, as well as the PBLH (Figure 6). This occurs as expected, because the increase of temperature leads to the intensification of convective process, which culminate in the rise of PBLH and rise of vertical wind. In the same way, the reduction of temperature generates the decrease of convective process and consequently the reduction of PBLH and variance of $w$.

The maximum of RCS's variance can be used as indicator of PBLH. It represents large variation in the aerosol concentration, which is the result of the rapid mixing of air parcels located above the top of PBL (therefore with lower aerosol backscatter coefficient values) with others situated inside the convective boundary layer and consequently endowed with high aerosol concentration $[1,7]$. In Figure 7 we can see that there is a good agreement among variance, WCT and MWR methods as PBLH indicator, however the variance gets confused in presence of multiple aerosol layers indicating several maxima (13 to 14 UTC).

\section{CONCLUSIONS}

In this work we analysed the height and turbulent structure of PBL along the time. We obtained a good agreement between the PBLH 


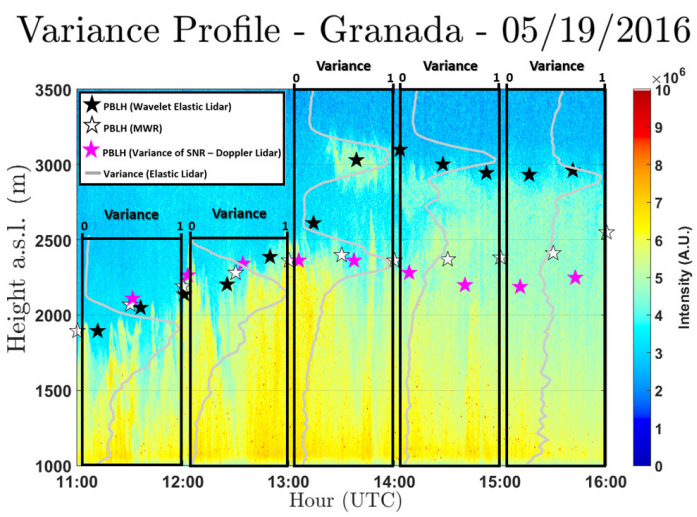

Figure 7: Variance - EL

detected by $M W R, E L$ and $D L$. In the same way the second order moment provided by $E L$ and $D L$ have a high resemblance between them and they together with temperature information help us to justify and understand better the process of increasing and decreasing of PBLH. The study confirms the feasibility of RSS to studies about turbulence in the PBL.

In future studies, we intend to apply this same methodology to obtain other high order moments (Skewness and Kurtosis) and to make the combination of DL and EL data to measure particle flux.

\section{ACKNOWLEDGEMENTS}

This work was supported by the Andalusia Regional Government through project P12-RNM2409, by the Spanish Ministry of Economy and Competitiveness through projects CGL201345410-R and CGL2016-81092-R and by the European Union's Horizon 2020 research and innovation programme through project ACTRIS-2 (grant agreement No 654109).The authors thankfully acknowledge the FEDER program for the instrumentation used in this work. This work was also partially funded by the University of Granada through the contract "Plan Proprio. Programa 9. Convocatoria 2013" and CNPq by scholarships from "Ciên- cias sem Fronteiras (Convocatória 2015") and "Doutorado GD - Processo:140017/2017-8".

\section{References}

[1] To-Prof Action. Definition of terminology related to PBL, 2015.

[2] Behrendt, A., Wulfmeyer, V., Hammann, E., Muppa, S. K., and Pal, S. Profiles of secondto-fourth-order moments of turbulent temperature fluctuation in the convective boundary layer: first measurements with rotational Raman lidar, Atmos. Chem. Phys., 15 (2015), 5485-5500.

[3] Coen, M. C., Praz, C., Haefele, A., Ruffieux, D., Kaufmann, P. and Calpini, B. Determination and climatology of the planetary boundary layer height above the Swiss Plateau by in situ and remote sensing measurements as well by the COSMO-2 model, Atmos. Chem. Phys., 14 (2014), 13205-13221.

[4] Pal, S., Behrendt, A., and Wulfmeyer, V. Elastic-backscatter-lidar-based characterization of the convective boundary layer and investigation of related statistics, Ann. Geophys., 28 (2010), 825-847.

[5] Lenschow, D. H., Wulfmeyer, V., Senff, C. Measuring Second-through Fourth-Order moments in noisy data, Journal of Atmospheric and Oceanic Technology, 17 (2000), 1330 1347.

[6] Moreira, G. de A., Marques, M. T.A., Nakaema, W., Moreira, A. C. de C. A., Landulfo, E. Planetary Boundary Layer height estimation from doppler wind lidar measurements, radiosonde and hysplit model comparison, Óptica Pura y Aplicada, 48 (2015), 179-183.

[7] McNicholas, C., Turner, D. D. Characterizing the convective boundary layer turbulence with a High Spectral Resolution Lidar, Journal of Geophysical Research Atmospheres, 119 (2014), 910 - 927. 